\title{
O DESENCANTO SEDUTOR: A IDEOLOGIA DA RACIONALIDADE TECNOLÓGICA
}

José Leon Crochík

\section{RESUMO}

Este ensaio tem como objetivo discutir o conceito de ideologia da racionalidade tecnológica, com base na teoria crítica da sociedade.

Palavras-chave: ideologia da racionalidade tecnológica, teoria crítica da sociedade.

\section{INTRODUÇÃO}

O conceito de cultura, assim como o seu objeto, é inseparável do conceito de civilização. A liberdade que a cultura pode expressar e realizar depende do progresso material. Como esse progresso não é linear e não pode ser pensado unicamente por sua vertente de desenvolvimento, devemos considerar que o progresso da civilização também contribui com o regresso: a presença da barbárie, contra a qual aquele se define.

Com a divisão do trabalho cada vez mais racionalizada, a diferenciação das esferas sociais diminui, e a socialização cada vez mais ampla, produto do progresso da sociedade administrada, retira a possibilidade do particular - o indivíduo que se expressa e se contrapõe

\footnotetext{
* Professor Livre-Docente pelo Instituto de Psicologia da USP; docente dos Programas de Estudos Pós-Graduados em Educação: História, Política, Sociedade e em Psicologia Social da Pontifícia Universidade Católica de São Paulo; docente do Instituto de Psicologia da USP e pesquisador do Conselho Nacional do Desenvolvimento Científico e Tecnológico - CNPq, ao qual o autor agradece pelo apoio financeiro. [e-mail: jlchna@usp.br]
} 
ao geral - diferenciar-se. Com o indivíduo e as instituições cristalizados, aquilo que não é previsto na racionalidade dominante só pode ser enunciado na negação, na rebelião. Assim, o progresso, que permite uma vida mais confortável e segura, colabora também com a imobilização social e com a infelicidade humana. Os desejos que não podem ser expressados - e, antes disso, conhecidos - buscam a realização por formas perversas, contrapondo-se à sociedade. Se a realização desses desejos compactua com a barbárie, ao mesmo tempo, denuncia a injustiça social, expressada pela dominação de um interesse formal, pretensamente unitário. Em outras palavras, a socialização total contrapõe-se à individuação, e o indivíduo torna-se hostil à civilização. Isso só pode ocorrer pela cisão imposta ao homem entre racionalidade e irracionalidade. Essa última encontra diversos caminhos para se apresentar, inclusive e paradoxalmente, por meio da própria racionalidade. Assim, na mais abstrata racionalidade, podem ser encontrados os desejos mais primitivos. De outro lado, a racionalidade também é irracional, uma vez que não procede dos verdadeiros interesses humanos, mas dos interesses do capital. Dessa forma, há algo de racional na irracionalidade dos desejos, presente na acusação que ela implica, e há algo irracional na racionalidade social, pelo desconhecimento dos desejos humanos.

Na sociedade administrada, a contradição social, se ainda é expressada pela luta de classes, apresenta-se também ao obstar aquilo que já seria possível: a autonomia de decisão individual, a espontaneidade, que se associa ao novo, uma vida sem ansiedade, uma vida sem a obrigatoriedade de tanto trabalho. Os meios - a técnica, a coletividade, a razão - tornam-se fins, o fim é esquecido: uma vida digna de ser vivida. Como a emancipação é freada, resta a adaptação ao existente, mas a adaptação a uma sociedade irracional, que insiste em fixar os indivíduos em um estágio infantil de desenvolvimento, no qual o prazer se associa com a crueldade e não com o amor; mesmo esse é vivido na competição, na frieza dos parceiros que compartilham interesses de sobrevivência, até que esses interesses tornem-se antagônicos no casal. Até para aqueles que se encontram numa situação material razoavelmente segura, a ameaça do desamparo é real, e as ilusões que tentam negar esse desamparo são fornecidas, 
na atualidade, pela ideologia da racionalidade tecnológica, reproduzida também pelos meios de comunicação de massa.

Tais ilusões expressam-se na crença de que unicamente com o progresso os problemas sociais e individuais serão resolvidos. Certamente, o progresso é contraditório, alia-se também à possibilidade de emancipação, ao criar condições para uma vida mais confortável e segura para todos, mas como o progresso é também progresso da dominação, a regressão é inevitável. Em outras palavras, se a riqueza social aumenta, mas as relações de produção permanecem as mesmas, a dominação de uma classe social sobre outra se reproduz, oculta pela aparente neutralidade do progresso. Esse se outrora servia simultaneamente ao capital e à humanidade, numa sociedade de produção abundante, serve, predominantemente, ao capital.

Assim, é necessário redirecionar o progresso politicamente para que continue a gerar condições de libertação das relações de produção. Com a riqueza social acumulada, o progresso deveria ser mais associado ao progresso da consciência que perceba a dominação, onde quer que essa se apresente, do que à criação de mais riquezas, que auxilia a perpetuação da dominação.

Como essa ideologia substitui a realização de valores humanos, possibilitados pela negação determinada da sociedade existente, pela adaptação eficiente à realidade estabelecida, a consciência social reduz-se à consciência individual. e todos os recursos para a sobrevivência são justificados, uma vez que se trata da sobrevivência, fortalecendo-se, dessa maneira, o cinismo e a frieza. A ênfase que a indústria cultural dá à cidadania, à participação democrática para tornar a sociedade mais justa pertence ao conjunto de ilusões destinado a pregar esperanças numa sociedade anacrônica, ou seja, que já esgotou as suas possibilidades de realização de felicidade, liberdade e justiça. A adesão do indivíduo a essas ilusões não se dá da mesma forma que a que ocorria, no século XIX, à ideologia liberal, que continha alguma racionalidade que permitia a crítica à sociedade existente.

Como a felicidade, a liberdade e a justiça são atreladas, nos dias que correm, à adaptação e não à sua superação, que exige a superação da atual sociedade, elas têm o seu conteúdo reduzido ao que é possível no presente. Deve-se considerar que se é feliz por ter 
um emprego, ou seja, por estar submetido ao capital, por poder satisfazer as necessidades criadas pelas necessidades de reprodução do capital, por poder ser admirado, isto é, invejado, pelos outros, pois isso permite a impressão de ser superior aos outros - e assim poder estar mais afastado das desgraças que a miséria material e psíquica possibilita; deve-se considerar que se é livre, autônomo, quando se consegue optar pelo mal menor, quando se pode decidir a qual senhor servir, sem a percepção de que todos os senhores são similares; devese considerar justo, quando formalmente a igualdade é mantida tendo por base a desigualdade. $\mathrm{O}$ formalismo, presente na ideologia da racionalidade tecnológica, transforma o desigual em igual, o infeliz em feliz, o oprimido em livre e o injusto em justo, ao negar as condições sociais que geram a infelicidade, a opressão e a injustiça.

O equivalente do capital, que transforma os valores de uso em valor, o equivalente do pensamento formal, que torna todos os objetos intercambiáveis, retiram a substância da vida. Assim, a defesa da democracia formal, e não da plena democracia, da cidadania formal, e não da plena cidadania, auxilia na criação de uma consciência expropriada de si mesma, ou seja, que se impede de perceber o que se percebe: a miséria existente, que não se restringe à miséria material encontrada em países como o nosso, mas que abrange também a miséria psíquica, que não é determinada psiquicamente.

A negação do que se percebe é gerada pela ameaça à sobrevivência, e o que se percebe é mantido próximo à consciência, gerando um conflito que leva ao fortalecimento daquela negação: quanto mais se percebe a contradição social, menos ela deve ser percebida e, assim, como argumentam Adorno e Horkheimer (1985), quanto menos se acredita mais se deve acreditar. A possibilidade de felicidade, justiça, liberdade, democracia, cidadania, nesta sociedade, é mentira manifesta, e dessa maneira a consciência deve aderir ao que é falso.

A justificativa dessa adesão é permeada por argumentos formais, racionais, técnicos, que ilustram a plena adaptação: deve-se trabalhar para aumentar a riqueza social (quando a riqueza existente é suficiente para eliminar a miséria da Terra) e para melhorar as condições de vida individual (quando já poderíamos reduzir intensamente a jornada 
de trabalho e ter tempo para viver); deve-se estudar para obter melhores empregos (quando, pelo avanço da automação e redução do mercado de trabalho, os empregos são cada vez mais raros); devese votar corretamente para a escolha de um bom dirigente político (quando os limites da ação política são restritos). Assim, nesta sociedade, quanto mais felizes, livres e justos nos consideramos, menos felizes, livres e justos somos, e colaboramos para continuar assim.

Pelo aparente distanciamento das forças produtivas das relações de produção, o ajuste técnico é imposto em todas as esferas: os problemas individuais são considerados desajustes pessoais, que a psicoterapia pode solucionar; os problemas de aprendizagem são ou falhas do aluno ou do professor, e um método tecnicamente desenvolvido pode resolvê-los; os problemas políticos são convertidos em problemas administrativos; a pobreza individual resolve-se presumidamente pela educação para o trabalho e com a criação de empregos. Para tudo há solução, quando se considera quer o indivíduo, quer a sociedade, como sistemas, cujas falhas podem ser resolvidas tecnicamente.

Se a contraposição entre racionalidade e irracionalidade, existente no século XIX, permitiu a cisão entre consciente e inconsciente, descrita por Freud, no século XX, devido ao término do mercado livre e ao surgimento dos monopólios e oligopólios, ela se tornou anacrônica. Com a socialização total não há mais, no limite, nenhum esconderijo, nenhuma intimidade, nenhum segredo que o indivíduo possa ter; a cultura, por sua vez, ao invés de possibilitar a elaboração do irracional, serve-se dele, para se vender, justificandose como se fosse voltada aos interesses individuais. De fato, o que ela produz não é indiferente aos indivíduos, mas atende a desejos primitivos. O primitivismo não é superado, mas fortalecido pela ordem racional.

O indivíduo não se volta mais para a cultura, essa se volta contra ele, permitindo que, pela realização de seus desejos não diferenciados, se identifique com ela. A regressão do indivíduo é decorrência da não diferenciação social possibilitada pelo processo de racionalização social, que torna todas as esferas sociais semelhantes quanto à sua racionalidade: a reversibilidade e a 
correspondência lógica - a reciprocidade - não são mais princípios exclusivos da lógica formal, mas também das relações individuais e das relações sociais.

Os desejos de competição, o sadismo e o masoquismo são propícios a uma sociedade hierárquica que substitui os indivíduos segundo as suas necessidades. O masoquismo está presente na felicidade de se estar submetendo a um sistema social opressivo das qualidades individuais, e o sadismo, na exigência que os outros façam o mesmo. A eliminação do adversário, que é tornado inimigo, é permeado pela crueldade, presente no sadismo e no masoquismo e na sensação de se supor superior aos outros. Quando alguém é promovido, quando consegue comprar um produto, que não precisa, mas aumenta o prestígio social, algo da crueldade está presente. $\mathrm{O}$ prazer em nossos dias, como dito antes, é associado à crueldade e não ao amor. Mas a crueldade, segundo Adorno e Horkheimer (1985), é formação reativa ao desejo de proximidade dos homens, à solidariedade, e, dessa forma, sendo cruéis, involuímos. O ajustamento técnico individual às necessidades de reprodução do capital consiste na justificativa daquelas necessidades individuais que deveriam ser superadas na formação do homem civilizado, entre elas, a crueldade, a competição. Os que formam os indivíduos para a adaptação à sociedade existente procuram fortalecer a dureza, a frieza, e não o que pressupõe a humanidade: a sensibilidade para o sofrimento, para a identificação. Claro que a ação técnica exige a dureza e a frieza e que a técnica não serve unicamente à regressão, mas uma educação, digna desse nome, deveria considerar a contradição presente na formação técnica.

Do parágrafo anterior depreende-se que, subjacente ao uso da tecnologia, estão presentes os desejos de destruição: a crueldade, o sadismo, o masoquismo, a eliminação do adversário. Isso, por si só, indica que a técnica não possui a neutralidade que se supõe; antes, essa suposta neutralidade serve como racionalização para a realização daqueles desejos, presentes naquele que é responsável pelos cortes de empregos numa empresa, que, ao se utilizar de procedimentos técnicos envolvidos na fórmula "custos/benefícios", se satisfaz com o seu poder, ou naquele que se sente feliz porque consegue entregar 
os seus trabalhos no tempo previsto, sem se perguntar para que eles servem.

A cultura colabora, por meio da ideologia, para a manutenção de uma sociedade injusta, e é injusta, diga-se de passagem, com todos os homens. Com o desgarramento entre o indivíduo e a sociedade, o primeiro é mais do que nunca determinado pela última, e os homens se convertem em seus apêndices. A crítica feita, desde Marx (1984), era dirigida ao capital e não ao capitalista; a relação que examinava era a existente entre o capital e o trabalho, e não diretamente a que há entre o capitalista e o trabalhador. Se na época de Marx, no entanto, essa última relação promovia efetivamente mudanças cruciais, nos dias que correm, a relação formal toma o lugar de seu objeto, tornandose independente dele. É nesse sentido que podemos falar de sociedade administrada. A neutralidade dos conceitos de administração, de ordem, de progresso, de técnica permite a sua universalização, e oculta as suas contradições.

O que permite a adaptação a uma sociedade contraditória é a ideologia, que substitui, em grande parte, a força bruta direta necessária para que a ordem social se mantenha segundo os interesses dominantes, mas a ameaça da força é a sua substância. Assim, a consciência não reage diretamente ao conteúdo da ideologia, mas à ameaça. O que nos faz trabalhar continuamente é menos a justificativa ideológica e mais o medo do que aconteceria se assim não o fizéssemos.

A ideologia, contudo, é histórica, e sua forma, seu conteúdo e, portanto, a sua relação com os indivíduos se transformam. Na época de Freud, boa parte dos homens internalizava a ideologia e defendia o status quo por medo do superego. Com o enfraquecimento da autoridade, os indivíduos não mais internalizam - são instrumentalizados. Isso implica que a própria ideologia que, por se voltar para a consciência, tinha de ser racional, possa perder a racionalidade e ter como justificativa unicamente a necessidade de sobrevivência. A ameaça à vida hoje não é menos imediata do que a do século do liberalismo, mas o conteúdo que a ideologia atual propaga é, segundo Habermas (1983), simultaneamente, mais e menos racional do que a anterior. Mais racional porque acentua as condições da emancipação da miséria, por meio do avanço tecnológico; menos racional porque 
se distancia mais dos interesses verdadeiramente humanos, ao que acrescentaríamos que a sua racionalidade é aparente, uma vez que reproduz as relações de produção, e, assim, quanto maior o progresso material, maior é a dominação social; claro que isso não elimina a importância do progresso na sociedade existente, tendo em vista o que resulta em menor sofrimento humano, mas permite visualizar o que se mantém presa da dominação: a consciência.

$\mathrm{O}$ conceito de ideologia da racionalidade tecnológica refere-se ao mundo desencantado, analisado por Adorno e Horkheimer (1985), e à sociedade industrial, descrita por Marcuse (1982). Como esse conceito não pode ser compreendido sem a análise da sociedade que a configura, deve-se sempre ter presente a estrutura social que lhe dá origem, ocultando-se sob ela, e a consciência à qual se destina. Se essa ideologia corresponde à sociedade administrada, a sua gênese encontra-se na origem da nossa sociedade, o que implica que ela permeou as ideologias anteriores, ainda que não se destacasse, mesmo porque numa sociedade menos organizada e com escassez de produção, os conflitos sociais podiam ser enunciados em outros termos. Em épocas anteriores, o trabalho e o avanço técnico eram necessários para a criação das condições para a libertação da carência material; podiam ser defendidos por trabalhadores e por capitalistas; na sociedade atual, caracterizada pela abundância da produção, não têm mais justificativa racional.

A ideologia da racionalidade tecnológica mostra a verdade da ideologia liberal do século XIX, que combatia qualquer intervenção na conduta individual nos domínios econômico e político, e a da ideologia liberal do século XX que, pregando a igualdade de oportunidades, pede a intervenção do Estado, culminando no estado do bem-estar social. A liberdade é em ambos os casos controlada, o que define uma sociedade que se encaminha para a administração completa, sob a qual continuam se ocultando os interesses da classe social que detém o poder político e econômico.

Se a ideologia que estamos analisando tem a sua gênese nos primórdios de nossa civilização, ainda que não se manifestasse plenamente, devemos buscar no passado as condições que a geraram, não sem antes realçar que o seu conteúdo expressa-se pela sua forma, 
enquanto, nas ideologias anteriores, o conteúdo estava em primeiro plano, e que, outrora, necessidades objetivas podiam emprestar à ideologia alguma racionalidade, que está ausente na atual.

A seguir apresentaremos alguns elementos presentes na obra dos autores da teoria crítica da sociedade que explicitam o que desenvolvemos até aqui sobre a ideologia e suas relações com as condições objetivas de produção. Algumas repetições serão inevitáveis, mas servirão para fortalecer algo que é pouco discutido nos nossos dias, quando as atenções daqueles que voltam a sua crítica à ideologia a restringem, de um forma geral, à ideologia liberal, ou à sua nova forma, que representa o seu declínio, a ideologia neoliberal.

Segundo Adorno e Horkheimer (1985, p. 59-60), a ideologia já se apresentava nos mitos da Antiguidade:

A interpretação mágica e coletiva do sacrifício, que nega totalmente sua racionalidade, é a sua racionalização; mas a hipótese esclarecida e linear de que o que hoje seria ideologia poderia ter sido outrora verdade é ingênua demais: as ideologias mais recentes são apenas reprises das mais antigas, que se estendem tanto mais aquém das ideologias anteriormente conhecidas quanto mais o desenvolvimento da sociedade de classes desmente as ideologias anteriormente sancionadas. A irracionalidade tão invocada do sacrifício sobreviveu à sua própria necessidade racional, que já constituía uma inverdade, isto é, já era particular.

Os autores estão analisando a Odisséia, de Homero, para pensar o conceito de sacrifício utilizado no fascismo. Como reprise das ideologias mais antigas e sem a presença da racionalidade que o legitime, o sacrifício presente na ideologia fascista é mentira manifesta. Como justificativa de dominação, como verdade particular que se pretende universal, auxilia a manter a dominação de poucos sobre muitos.

Ao buscar a origem do capitalismo e do pensamento burguês na Antiguidade, os autores propõem que esses sejam analisados à luz da necessidade de autoconservação. Em outras palavras: a dominação sobre a natureza externa ao homem, para que esse se constituísse e se mantivesse, é correlata da dominação dos homens sobre si mesmos 
e sobre os outros homens. A divisão do trabalho e a propriedade são expressões dessa dominação. Quanto à primeira alegam:

Nas primeiras fases do nomadismo, os membros da tribo têm ainda uma parte autônoma nas ações destinadas a influenciar o curso da natureza. Os homens rastreiam a caça, as mulheres cuidam do trabalho que pode ser feito sem um comando rígido. Quanta violência foi necessária antes que as pessoas se acostumassem a uma coordenação tão simples como essa é impossível determinar. (ADORNO; HORKHEIMER, 1985, p. 34)

A divisão das tarefas ainda não separou rigidamente comando e trabalho como acontecerá por meio da propriedade fixa: "Com o fim do nomadismo, a ordem social foi instaurada sobre a base da propriedade fixa. Dominação e trabalho separam-se" (Adorno; HorKHEIMER, 1985, p. 28). A unidade dos deuses no deus único, a unidade do comando têm como contrapartida a fixação dos trabalhadores à terra. Assim, esses autores dizem que a dominação da lógica se eleva, mas se funda na dominação real.

A dominação presente no esclarecimento, contudo, guarda as sementes da liberdade:

Os instrumentos da dominação destinados a alcançar a todos - a linguagem, as armas e por fim as máquinas - devem se deixar alcançar por todos. É assim que o aspecto da racionalidade se impõe na dominação como um aspecto que é também distinto dela. A objetividade do meio, que o torna universalmente disponível, sua 'objetividade' para todos, já implica a crítica da dominação da qual o pensamento surgiu, como um de seus meios. (ADORNO; HORKHEIMER, 1985, p.48)

A dominação da natureza, se é necessária para o afastamento do homem daquela, para que pudesse se constituir, não se justifica como inerente à natureza humana. É justamente essa dominação que os autores entendem que deveria ser superada e não continuamente justificada por meio de sua naturalização. A percepção de que a história seja permeada pela violência não permite hipostasiá-la. 
A lógica da ideologia da dominação, que se esconde por intermédio da administração racional, e que se justificava pela escassez, como dito antes, perdeu o seu fundamento e, assim, não é inevitável. Se são as condições concretas do trabalho que produzem a impotência dos trabalhadores, por perderem a sua justificativa racional - a escassez -, só continuam a existir para perpetuar o poder existente.

Dessa forma, o mundo desencantado, analisado por Adorno e Horkheimer (1985), traz como prisioneira do encanto a necessidade de dominação. Essa necessidade é produto do esclarecimento, processo destinado a nos livrar das trevas e do medo, que, na sua iluminação excessiva, oculta a dor do sacrifício contínuo. Como algo foi perdido no tempo mais remoto, quando a própria noção de tempo não poderia ter sido formulada, quando, ao contrário, esse parâmetro da civilização já é defesa contra o que ameaça renascer, o fechamento do universo por meio das categorias do pensamento, que uniformizam dentro de um sistema a multiplicidade da vida, busca incessantemente liquidar o que não se compõe com aquelas categorias: a história, a natureza, a subjetividade que não se submete e renuncia ao senhorio.

A má consciência que gera essa renúncia busca em um futuro aprisionado o que abandonou no passado. O que está na base dessa procura é a nostalgia da felicidade sem ameaças. De outro lado, a felicidade possível na sociedade burguesa, marcada pela separação entre o mundo da matéria e o do espírito, traz como limite o mal menor: a cultura não consegue cultivar o que é sem limites, o que é imprevisível, mas assim torna-se tão repetitiva quanto a natureza que quer dominar e substituir.

A divisão entre trabalho manual e trabalho intelectual é o que permite o surgimento da práxis que só tem sentido quando voltada para a libertação do trabalho alheio ao homem, que o despossui de sua humanidade. Mas aquela divisão também é a gênese da ideologia que a perpetua. A distância entre o senhor-que administra o trabalho - e o trabalhador, que por se pôr entre o senhor e o produto não o permite usufruí-lo, impede a felicidade de ambos. A insígnia dessa relação se apresenta, segundo Adorno e Horkheimer (1985), na Odisséia, de Homero, nas duas possibilidades que Ulisses - o senhor - desenvolve para quebrar o contrato previsto para aqueles que 
ousassem passar pelas sereias: tapar os ouvidos dos remadores, para que esses sequer saibam da existência do prazer do canto das sereias, e prender a si próprio no mastro da embarcação, ouvindo o apelo das sereias, mas não se entregando a ele.

A automutilação de Ulisses marca a condenação do indivíduo burguês a não poder realizar as promessas de felicidade contidas no passado. O mito destrói o esquema de partição do tempo linear que separa passado, presente e futuro. Ulisses, para se manter vivo, deve romper consigo mesmo, cindir-se, negando a felicidade atemporal, na qual o reencontro é sempre possível. Para se diferenciar da natureza e dominá-la, deve dominar a própria natureza, os próprios desejos. A sua astúcia, base da razão moderna, separa a coisa do nome, tornandose senhor da coisa nesse mesmo ato. A palavra, por pertencer ao sujeito e designar a coisa, garante a liberdade do primeiro, mas o aprisiona a ela. Se alguém pode denominar-se ninguém, ninguém pode ser alguém. Doravante, o que o sujeito é depende da nomeação que pretende sobreviver à coisa nomeada.

A ocultação de si mesmo, a partir de um nome que pode ser atribuído a qualquer um, é a aparência que define a essência do indivíduo burguês: ele é o que aparece, mas o que deixa de ser com isso - natureza desejante - perde-se no passado mítico. Caminhando entre a autoconservação e a autodestruição, o indivíduo embriaga-se de sua aparência. $\mathrm{O}$ desespero gerado no primitivo diante das forças de Mana se mantém naquele que as domina.

Em Adorno e Horkheimer (1985) e em Freud (1986), o progresso da cultura traz a marca da ilusão da vitória sobre o passado, pois não se direciona para a felicidade dos homens, mas para a sua ruína constante, na medida em que cada vez mais se nega a eles aquela felicidade. Por trás da dominação contínua, a promessa de felicidade continua a se alimentar dos despojos. O mito do progresso infinito traz consigo o encantamento do desencantado, cortina de fumaça do desejo negado.

A ideologia como negação da dominação é a dominação da consciência. Essa que se constitui na relação com o outro, relação essa mediada pela sociedade, é presa da palavra. O nominalismo que combate a universalidade humana, possível através da diferenciação 
dos homens, afirma o sujeito absoluto no seu relativismo. Tornando a linguagem um conjunto de signos neutros intercambiáveis entre si nas fórmulas do entendimento, o esclarecimento apresenta uma segunda prisão: o desconhecimento do que não pode ser nomeado:

O eu, que aprendeu a ordem e a subordinação com a sujeição do mundo, não demorou a identificar a verdade em geral com o pensamento ordenador, e essa verdade não pode subsistir sem as rígidas diferenciações daquele pensamento ordenador. Juntamente com a magia mimética, ele tornou tabu o conhecimento que atinge efetivamente o objeto. (AdORNO; HorkHEIMER, 1985, p. 28)

A liberdade da palavra em face da coisa nomeada, no entanto, permite também a liberdade da repetição, desde que não se caia em outra repetição. Assim, o espírito que se julga independente da autoconservação é também verdadeiro. A palavra é materialidade humana; com ela é possível dar outros sentidos à repetição, libertandoa desse destino. Mas a relação que permite ter com o objeto nomeado não deve ser restrito ao para si humano, pois isso torna esse natural. Quando o sujeito não pode ser pensado também como objeto, mutilase, desconhecendo as suas determinações, e assim impede-se também de conhecer o objeto.

A tentativa, porém, de se golpear a palavra, na sua possibilidade de libertar o objeto, a serviço de uma visão objetivista da realidade, torna essa última prisioneira de si mesma. E assim o que aparece como supérfluo, dependente, determinado, é o que é negado como essencial e independente: o vir-a-ser humano.

A práxis, ligada desde a origem ao trabalho, traz a promessa da liberdade desse sujeito:

A práxis nasceu do trabalho. Alcançou seu conceito quando o trabalho não mais se reduziu a reproduzir diretamente a vida, mas sim pretendeu produzir as condições desta: isto colidiu com as condições então existentes. $\mathrm{O}$ fato de se originar do trabalho pesa muito sobre toda práxis. Até hoje acompanha-a o momento de não-liberdade que arrastou consigo: que um dia foi preciso agir contra o princípio do prazer a fim de conservar a própria existência; 
embora o trabalho, reduzido a um mínimo, entretanto não mais precisasse continuar acoplado à renúncia. (ADORNo, 1995, p. 206)

Adorno aponta, nesse trecho, para a falsidade existente na ideologia da necessidade do trabalho, quando não há mais necessidades objetivas que o justifiquem na mesma medida de outrora. O sujeito preso ao mundo da autoconservação, ou seja, à necessidade de trabalhar, mantém-se na prisão, a liberdade reside fora do mundo do trabalho:

A ideologia da escassez, da produtividade do esforço de trabalho, dominação e renúncia é desalojada de suas bases instintivas e racionais. A teoria da alienação demonstrou o fato de que o homem não se realiza em seu trabalho, que a sua vida se tornou um instrumento de trabalho, que o seu trabalho e os respectivos produtos assumiram uma forma e um poder independentes dele como indivíduo. Mas a emancipação desse estado parece requerer não que se impeça a alienação, mas que esta se consuma; não a reativação da personalidade reprimida e produtiva, mas a sua abolição. A eliminação das potencialidades humanas do mundo de trabalho (alienado) cria as precondições para a eliminação do trabalho do mundo das potencialidades humanas. (MARCUSE, 1981, p. 103)

A realização efetiva do homem, a possibilidade de viver a vida como um fim em si mesmo, depende de sua retirada do mundo do trabalho alienado. Esse, contudo, tem sido a base da constituição do indivíduo desde a Antiguidade, aparentado que foi a idéia de sacrifício em nome da coletividade. Isso significa que o que conhecemos como indivíduo, nos dias de hoje, é a sua negação. Assim é que Adorno (1985) afirma que todo ideal de homem é ideologia, a não ser aquele que é negado. Mas é ideologia, em um sentido distinto daquele dado à ideologia liberal. Nessa, o que era falso residia na sua tentativa de realizar o seu conteúdo, independentemente das condições objetivas que impediam essa realização. A sua veracidade encontrava-se quer em seu conteúdo - indivíduo, liberdade, felicidade, propriedade -, quer em sua tentativa de ir além de seus condicionantes. 
Essa ideologia, segundo Adorno e Horkheimer (1973, p. 193), corresponde a uma sociedade complexa, a hodierna refere-se a uma sociedade simplificada em sua estrutura:

A ideologia, em sentido estrito, dá-se onde regem relações de poder que não são intrinsecamente transparentes, mediatas e, nesse sentido, até atenuadas. Mas, por tudo isso, a sociedade atual, erroneamente acusada de excessiva complexidade, tornouse demasiado transparente.

Segundo esses autores, a ideologia perdeu a sua relativa autonomia, ou seja, o que tinha de verdadeiro: a possibilidade de se pensar além do existente, e assim limita-se à reprodução desse. Com essa modificação da ideologia, a crítica ideológica também deve alterarse, pois essa só é possível quando algo de racional persiste na ideologia:

Por isso, a crítica ideológica, como confronto da ideologia com a sua verdade íntima, só é possível na medida em que a ideologia contiver um elemento de racionalidade, com a qual a crítica se esgote. Assim acontece com idéias tais como as de liberalismo, individualismo, identidade entre espírito e a realidade. Entretanto, quem se dispusesse a criticar desta maneira a chamada ideologia do nacional-socialismo, acabaria sendo vítima da sua desapontadora ingenuidade. (AdORNO; HorKHEIMER, 1973, p. 191)

Esses autores alegam que, atualmente, mais do que criticar o conteúdo da ideologia, dever-se-ia entender o que leva os indivíduos a aderir a algo manifestamente falso. Esse foi, ao que parece, um dos objetivos do estudo sobre a personalidade autoritária, que foi mal compreendido por diversos pesquisadores. Uns desconsideraram o conteúdo político da elaboração das escalas preparadas nesse estudo e se limitaram a criticar as falhas experimentais e a validade da escala F para mensurar o autoritarismo (ver Carone, s.d., e Vagostello, 1997); outros (ver Monteiro, 1996) consideraram-no um estudo sobre personalidade e não sobre a relação dessa com a ideologia.

Tal não é o entendimento de Rouanet (1989, p. 162). Para esse autor, The authoritarian personality é um 
[...] livro em que os autores procuram examinar, concretamente, ao nível da consciência individual, a forma pela qual se dá a interseção entre a ideologia e a estrutura da personalidade.

É importante frisar a falsidade inerente à ideologia atual que tem como um de seus principais traços fixar-se ao existente, dificultando a possibilidade de se pensar a transformação social necessária para uma sociedade justa. Se a ideologia atual tenta preservar o existente, a única alternativa que resta aos homens é a de se adaptar ou, em outras palavras, tornarem-se o que já são. Como não há possibilidade de transformação, só cabe aperfeiçoar o que existe.

O século XIX caracterizou-se pela primazia das leis do mercado. $\mathrm{O}$ crescimento da sociedade dependia do aumento da produção material. No século XX, com a passagem do capitalismo concorrencial para o de oligopólios e monopólios, a produção se racionalizou a tal ponto, com o auxílio da ciência e da tecnologia, que os trabalhadores já não têm a mesma importância para a produção que tinham no século anterior. A consciência de que a produção material é abundante e que portanto as leis básicas da economia já não são necessárias para que a sociedade possa emancipar-se do estado de miséria abundante já se apresentava na década de 1940, do século passado:

Hoje, com a metamorfose que transformou o mundo em indústria, a perspectiva do universal, a realização social do pensamento, abriu-se tão amplamente que, por causa dela, o pensamento é negado pelos próprios dominadores como mera ideologia [...] Os próprios dominadores não acreditam em nenhuma necessidade objetiva, mesmo que às vezes dêem esse nome a suas maquinações. Eles se arvoram em engenheiros da história universal. Só os dominados aceitam como necessidade intangível o processo que, a cada decreto elevando o nível de vida, aumenta o grau de sua impotência. Agora que uma parte mínima do tempo de trabalho à disposição dos donos da sociedade é suficiente para assegurar a subsistência daqueles que ainda se fazem necessários para o manejo das máquinas, o resto supérfluo, a massa imensa da população, é adestrado como uma guarda suplementar do sistema, a serviço de seus planos grandiosos para o presente e o futuro. 
Eles são sustentados como um exército dos desempregados. (AdORNO; HorKHEIMER, 1985, p. 48-49)

Esse longo trecho, publicado em 1947, aborda, ao menos, os seguintes pontos que contêm atualidade: 1 . a questão de que os problemas sociais de nossa época não dizem respeito, principalmente, à produção material, mas a questões políticas; e 2. a presença da automação na esfera da produção, que dispensa gradativamente o uso de mão-de-obra humana. Claro, os autores escreveram o texto nos Estados Unidos da América, um país do Primeiro Mundo, que desenvolveu as bases do estado de bem-estar social, tão almejado pelos países do Terceiro Mundo, mas Marcuse (1981, p. 18) aponta, após as críticas à miséria, principalmente psíquica, existente nos países que desenvolveram aquele tipo de Estado, que:

A vantagem histórica das nações mais novas, do seu atraso técnico, talvez seja a de poderem saltar o estágio de sociedade afluente. Os povos atrasados, por sua pobreza e fraqueza, poderão ser forçados a renunciar ao uso agressivo e supérfluo da ciência e da tecnologia, para manterem a engrenagem produtiva à la mesure de l'homme, sob o seu controle, para satisfação e desenvolvimento das necessidades vitais, tanto individuais como coletivas.

Esse trecho encontra-se no prefácio político escrito por Marcuse em 1966 à sua obra Eros e civilização. Após mais de três décadas, pode-se observar que: 1 . o estado do bem-estar social, que não era o melhor dos mundos possível, está deixando de existir nos países desenvolvidos, devido, também, à ação de governos neoliberais; 2 . os países do Terceiro Mundo continuam a seguir a tendência dos países do Primeiro Mundo, pressionados pelo processo de globalização; 3. a automação continua o seu avanço não só nos processos de produção material; 4. a produção ainda não se volta predominantemente para as necessidades vitais, mas para as necessidades do capital. Cabe realçar novamente que os autores citados são favoráveis à automação dos processos de produção para que o homem possa se constituir fora do mundo do trabalho alienado, mas resta pensar sobre a ideologia 
vigente que reforça a necessidade do trabalho material, quando ele não é necessário na medida em que o era tempos atrás e que, por isso, como dito antes, os entraves para uma sociedade justa não são de caráter econômico, mas de caráter político.

Poder-se-ia pensar que haveria a compensação do desemprego causado pela automação com a criação de novos empregos em outras áreas da economia, como a de serviços por exemplo, ainda que essa compensação só colaboraria para perpetuar o trabalho alienado que já poderia ser superado. E, de fato, o estudo de Lessa e seus colaboradores (1997, p. 73) mostra que, na década de 1990 do século passado, isso ocorreu no Brasil, mas trazendo consigo outros problemas. Dizem os autores:

De fato, os empregos criados em comércio e serviços entre 1991 e 1996 superaram em número os empregos destruídos pela indústria. Entretanto, se observarmos as características dos empregos criados, em face dos empregos perdidos, veremos que não cabe falar em "compensação". Também é verdade que o nível educacional dos postos criados é superior ao dos postos eliminados, mas pela natureza das novas ocupações, percebe-se que as diferenças em educação têm menos a ver com requisitos impostos por novas tecnologias e mais com o fato de serem ocupados por contingentes mais jovens e, por isso, com maior escolaridade.

Ou seja, a qualificação exigida nos novos empregos não é maior do que a que era necessária para os empregos anteriores (que é um dado importante para se pensar a ênfase dada atualmente para a educação no que diz respeito a uma maior qualificação profissional), os salários são mais baixos, e a escolaridade é maior. Em outras palavras, a modernização da economia tem exigido cargos não mais qualificados que os anteriores e de menores salários, ainda que possa contar com trabalhadores de maior nível escolar. Assim, a divisão de renda tende a uma concentração ainda maior.

Mais recentemente, a crise do desemprego aumentou, sem que tenha havido compensação à altura. Nas palavras de Singer (1998, p. 3): 
É claro que a quase estagnação da atividade industrial combinada com um aumento da produtividade do trabalho só poderia se traduzir num declínio muito forte do nível de emprego industrial, não compensado pelo aumento do emprego em serviços. Ou seja, a crise do desemprego se deve quase inteiramente à falta de crescimento da economia como um todo e do setor industrial em particular, que no passado recente sempre foi o motor da economia como um todo.

Se a atividade industrial diminui, o capital financeiro desenvolvese no mundo inteiro; parece que se está diante de uma solução inerente ao capital para suas crises de acumulação. O fenômeno da "mundialização do capital", como o denominou Chesnais (1998), não é novo, faz parte da tendência de expansão do capital para além das fronteiras nacionais. O que parece ser novo é a predominância do capital financeiro sobre o capital produtivo, o que acarreta a diminuição da produção de mercadorias e consequientemente de empregos.

O neoliberalismo é a doutrina política e econômica que prepara o terreno para que o capital financeiro possa adentrar nas nações. Os sindicatos dos trabalhadores precisam ser enfraquecidos para segurança dos investidores estrangeiros. Assim, não é casual que vários governos neoliberais combatam ostensivamente, no início de sua atuação, todo movimento reivindicatório dos trabalhadores. Certamente, a recessão econômica, que é marcadamente afetada por decisões políticas, prepara o terreno para enfraquecer o poder dos sindicatos. Mas o capital financeiro precisa de uma base produtiva para se sustentar, e assim a produção e o trabalho são necessários para mantê-lo.

Como é da manutenção do capital que se trata, os homens continuam alijados da vida, e a adesão à ideologia da racionalidade tecnológica continua a abrigar a esperança de que os homens ainda são necessários para a produção, pois converte uma situação política em técnica: basta, dizem alguns políticos e economistas, investir no desenvolvimento econômico para que a desigualdade diminua, sem ao menos mencionar a reprodução do capital, que não ocorre sem a exploração do trabalho e reproduz, ampliando-a, a desigualdade. 
A tecnologia que deveria servir à libertação da miséria material e psíquica, contraditoriamente, preserva as relações de produção existentes. Mediante a sua fachada de neutralidade traz a imagem que, com o seu desenvolvimento, pode-se alcançar um mundo melhor. Como as relações de produção, que já não se justificam objetivamente, mantêm-se reproduzindo o capital, a tecnologia traz o encanto do desencanto, ou seja, a ilusão de que a frieza existente é natural aos homens, dificultando a pergunta se poderia ser de outra forma.

A ideologia da racionalidade tecnológica, como ideologia moderna, traz como ilusão a possibilidade da perfeição do mundo existente, deixando-a de fora, o que impede um mundo justo. Como as contradições sociais acirram-se cada vez mais, mais se torna visível o seu caráter falso. Isso mantém as questões frankfurtianas: o que leva os indivíduos a aderir a um ideário contrário à racionalidade, ainda que aparentemente racional? Que transformações ocorrem na consciência individual para que essa adesão seja possível?

$\mathrm{O}$ mundo gira em falso. $\mathrm{O}$ trabalho, do qual já se poderia prescindir, torna-se imprescindível; a tecnologia que deveria libertar, aprisiona, e como a contradição é cada vez mais visível, a descrença é inevitável; contudo, quanto menos há fé, mais ela se torna necessária, e o indivíduo subjuga-se ao que é contrário aos seus interesses mais racionais. E dessa forma:

[...] precisamente porque a ideologia e a realidade correm uma para a outra; porque a realidade dada, à falta de outra ideologia mais convincente, converte-se em ideologia de si mesma, bastaria ao espírito um pequeno esforço para se livrar do manto dessa aparência onipotente, quase sem sacrifício algum. Mas esse esforço parece ser o mais custoso de todos. (Adorno; HORKHEIMER, 1973, p. 203)

\begin{abstract}
The aim of this essay is to discuss the concept of ideology of technological rationality, having at reference the Critical Social Theory
\end{abstract}

Key words: ideology of technological racionality; critical social theory. 


\section{REFERÊNCIAS}

ADORNO, T. W. Palavras e sinais - modelos críticos. 2. ed. Petrópolis: Vozes, 1995.

CARONE, Iray. Teoria crítica e psicologia social. São Paulo: EDUC, s.d. CHESNAIS, F. A emergência de um regime de acumulação financeira. In: Praga: estudos marxistas. São Paulo, Hucitec, ano 1, n. 3, 1997, p. 19-46.

FREUD, S. El malestar en la cultura. In: BRAUSTEIN, Nestor A.(Org.). A medio siglo de el malestar en la cultura de Sigmund Freud. México: Siglo Veintiuno, 1986.

HABERMAS, J. Técnica e ciência enquanto ideologia. In: Textos escolhidos. Benjamin, Horkheimer, Adorno, Habermas. 2. ed. São Paulo: Abril Cultural, 1983, p. 313-343. (Coleção Os Pensadores).

ADORNO, T. W.; HORKHEIMER, M. Dialética do esclarecimento: fragmentos filosóficos. 2. ed. Rio de Janeiro: Zahar, 1985.

. Temas básicos de sociologia. São Paulo: Editora Cultrix, 1978.

LESSA, C. et al. Pobreza e política social: a exclusão nos anos 90. In: Praga: estudos marxistas. São Paulo: Hucitec, ano 1, n. 3, 1997, p. 63-87.

MARCUSE, H. Eros e civilização. Rio de Janeiro: Zahar, 1981. 1982.

A ideologia da sociedade industrial. 6. ed. Rio de Janeiro: Zahar,

MARX, K. O capital: crítica da economia política. São Paulo: Difel, Livro I, v. $1,1984$.

MONTEIRO, M. B. Conflito e cooperação nas relações intergrupais. In: VALA, J.; MONTEIRO, M. B. Psicologia social. Lisboa: Fundação Calouste Gulbenkian, 1996. p. 309-352.

ROUANET, S. P. Teoria crítica e psicanálise. Rio de Janeiro: Tempo Brasileiro, 1989.

SINGER, P. A crise do desemprego. Jornal da Tarde. São Paulo, 12 mar. 1998.

VAGOSTELLO, L. A Ideologia involuntariamente sincera: uma análise da literatura científica inspirada em a personalidade autoritária nos últimos 16 anos (1980-1996), 1997. Dissertação (Mestrado em Psicologia) - Instituto de Psicologia, Universidade de São Paulo. 